\title{
A negative screen for mutations in calstabin 1 and 2 genes in patients with dilated cardiomyopathy
}

\author{
Diogo G Biagi ${ }^{1}$, José G Mill ${ }^{2}$, Alfredo J Mansur ${ }^{3}$, José E Krieger ${ }^{1}$ and Alexandre C Pereira ${ }^{\text {* }}$
}

\begin{abstract}
Background: Calstabins 1 and 2 bind to Ryanodine receptors regulating muscle excitation-contraction coupling. Mutations in Ryanodine receptors affecting their interaction with calstabins lead to different cardiac pathologies. Animal studies suggest the involvement of calstabins with dilated cardiomyopathy.

Results: We tested the hypothesis that calstabins mutations may cause dilated cardiomyopathy in humans screening 186 patients with idiopathic dilated cardiomyopathy for genetic alterations in calstabins 1 and 2 genes (FKBP12 and FKBP12.6). No missense variant was found. Five no-coding variations were found but not related to the disease.

Conclusions: These data corroborate other studies suggesting that mutations in FKBP12 and FKBP12.6 genes are not commonly related to cardiac diseases.
\end{abstract}

Keywords: Genetic screening, Calstabin, FKBP12, FKBP12.6

\section{Background}

Ryanodine receptors (RyRs) are the main proteins in the sarcoplasmic reticulum (SR) calcium-release channel and are modulated by other proteins in the regulation of muscle excitation-contraction coupling[1]. Calstabins 1 and 2 (FKBP12 and FKBP12.6 genes, respectively) bind both RyR1 (skeletal form) and RyR2 (cardiac form) although calstabin1 has higher affinity to RyR1, and calstabin2 to RyR2 [2-4]. The RyR-calstabin interaction occurs to stabilize the RyR channel in the closed state, but its specific amino acids binding site is still controversial [5-7]. Although, calstabin1 deficient mice display normal skeletal muscle phenotype, they have severe Dilated Cardiomyopathy (DCM) and ventricular septal defects [8]. Mice with a disruption in calstabin2 display hypertrophic cardiomyopathy only in males. However, both males and females present a similar dysregulation of $\mathrm{Ca}^{2+}$ release [9].

Disease-causing mutations in RyRs 1 and 2 affecting the interaction with calstabins were described as leading

\footnotetext{
* Correspondence: alexandre.pereira@incor.usp.br

'Laboratory of Genetic and Molecular Cardiology, Heart Institute, University of Sao Paulo Medical School, Brazil

Full list of author information is available at the end of the article
}

to different phenotypes [1]. Wehrens and colleagues reported RyR2 mutations which decrease the affinity of RyR2 with calstabin2 in patients with Catecholaminergic Polymorphic Ventricular Tachycardia (CPVT) [7]. However, no mutation in calstabin2 seemed to be involved with the disease [10]. The association of calstabins with heart disease was also tested in a familial Hypertrophic Cardiomyopathy cohort, and no mutation was found in all 252 patients [11]. Recently, Oyama and colleagues have reported an increased expression of FKBP12.6 gene in Great Dane dogs with DCM [12]. These results, taken together with the dilated cardiomyopathy phenotype of calstabin 1 knockout mice, suggest that calstabins may be associated with DCM development. Thus, the aim of the present study is to test the hypothesis that mutations in calstabins genes (FKBP12 and FKBP12.6) occur, and can cause human DCM phenotype.

\section{Results}

Considering the 186 Idiopathic Dilated Cardiomyopathy (IDC) patients screened, $75 \%$ were male and $25 \%$ female. The mean age was $44.8 \pm 12.4$. The population had the
Ciomed Central

() 2012 Biagi et al; licensee BioMed Central Ltd. This is an Open Access article distributed under the terms of the Creative Commons
Attribution License (http://creativecommons.org/licenses/by/2.0), which permits unrestricted use, distribution, and reproduction in any medium, provided the original work is properly cited. 
following ethnic distribution: $14.5 \%$ blacks, $15.5 \%$ mullatos and $69.8 \%$ whites.

No missense mutation was found in FKBP12 nor in FKBP12.6. Five new allelic variants were found (Table 1). Two of them were found in the control group (age and ethnic matched) with no significant difference in allelic nor genotypic frequency. Three allelic variants, one in the promoter region and two in the Exon1 5'UTR of FKBP12, were not present in the control group. Bioinformatics data suggest that these allelic variants have a very low or none probability to be pathological. From all SNPs found in our population, only one SNP with minor allelic frequency (MAF) not available in dbSNP was found (Table 2). All the alterations in cases and controls met the Hardy-Weinberg equilibrium.

\section{Discussion}

Data from animal models point out FKBPs as important candidate genes for cardiac diseases. In fact, several mutations in RyR1 and RyR2 proteins cause decreased affinity between RyRs and calstabins, leading to abnormal calcium cycling, a major hallmark of several cardiac phenotypes, including heart failure. Mutations affecting RyR-calstabin interactions are well described for some diseases such as: Left Ventricule Noncompaction (LVNC), Central Core Disease (CCD) and Catecholaminergic Polymorphic Ventricular Tachycardia (CPVT). However, little is known if mutations in calstabins could lead to disease by themselves. Genetic analyses of FKBP12 were done only in two cohorts of diseases (LVNC (48 patients) [13] and CCD (27 patients) [14]) and in one family with LVNC. No mutation was found in any of this studies. Recently, genetic analyses of FKBP12.6 have been done in 16 patients with CPVT and in 232 patients with hypertrophic cardiomyopathy and, also, no mutations were found.

To our knowledge, this study has been the first report of calstabins 1 and 2 genetic screening in idiopathic DCM patients. We found five new allelic variations and none of them caused amino acid change. The alterations c." $26 \mathrm{G}>\mathrm{A}$ in FKBP12.6 gene and $-40 \mathrm{C}>\mathrm{A}$ in $F K B P 12$ gene were also found in the control population. For the three other alterations we measured the risk of being disease-causing by the analyses of three different bioinformatics software, concerning their possible involvement in splicing, microRNA and transcription factor binding sites [15-17]. The -7G>A alteration in the promoter region of $F K B P 12$ was predicted as low risk, although its create a new biding site for the NRF2 transcription factor (TF). NRF2 enhances gene expression in response to oxidative stress, which is involved in the development and progression of heart failure $[18,19]$. This suggests that the $-7 \mathrm{G}>\mathrm{A}$ alteration could result in overexpression of $F K B P 12$ gene. Although overexpression of $F K B P 12$ gene has been described modulating RyR2 in rabbit myocytes [20], we believe that this mutation alone could not be responsible for disease development, once the concentration of calstabin1 in the heart is naturally much higher than calstabin 2 and does not hinder calstabin2 interaction with RyR2 [4]. Further studies are needed to assess the impact of the overexpression of calstabins1 in human cardiomyocytes. The c. $-72 \mathrm{C}>\mathrm{G}$ and c.$65 \mathrm{C}>\mathrm{G}$ alterations in the exon 15 'UTR region were predicted with none risk to be related with the disease. Overall, we did not find any alterations possibly related with the disease.

We found 7 silent SNPs with MAFs ranging between MAFs of European and African populations, which are the main founders of Brazilian population. Among the SNPs presented in the sequenced regions with allelic frequency described on dbSNP, only one was not found in our population (data not shown- rs77743612). This may be explained by its low MAF in the Yoruba population (0.014) and absence in the CEU population. Since these silent SNPs were not overrepresented in our population, it is quite improbable that they might be related with the disease.

Today, mutations in about 35 genes are described in idiopathic DCM. Together, they do not explain more than $10 \%$ of cases, indicating that more genes might be involved with the disease pathogenesis. Animal models suggested that calstabin proteins might be associated with DCM. Our result, taken together with other calstabin genetic screening efforts, leads us to believe that mutations in $F K B P 12$ and FKBP12.6 genes are not commonly related to cardiac diseases.

\section{Conclusion}

Calstabin 1 and 2 are not involved in idiopathic DCM development in Brazilian patients.

Table 1 New allelic variants found in FKBP12 and FKBP12.6 gene.

\begin{tabular}{ccccccc}
\hline Gene & Site & $\begin{array}{c}\text { MAF: cases } \\
(\mathbf{n}=\mathbf{1 8 6})\end{array}$ & $\begin{array}{c}\text { Reference } \\
\text { (coding DNA) }\end{array}$ & $\begin{array}{c}\text { MAF: controls } \\
(\mathbf{n}=\mathbf{2 8 8})\end{array}$ & $\mathbf{p}$ value & Risk by bioinformatics analyses \\
\hline FKBP12 & Promoter & 0.0026 & $-40 \mathrm{C}>\mathrm{A}$ & 0.0052 & 0.25 & - \\
FKBP12 & Promoter & 0.0026 & $-7 \mathrm{G}>\mathrm{A}$ & 0 & - & Low \\
FKBP12 & Exon 1 - 5' UTR & 0.0026 & C. $-72 \mathrm{C}>\mathrm{G}$ & 0 & - & None \\
FKBP12 & Exon 1 - 5' UTR & 0.0026 & C. $-65 \mathrm{C}>\mathrm{G}$ & 0 & - & None \\
FKBP12.6 & Exon 4- 3'UTR & 0.0026 & C. ${ }^{\prime} 26 \mathrm{G}>\mathrm{A}$ & 0.0017 & 0.55 & - \\
\hline
\end{tabular}


Table 2 SNPs found in FKBP12 and FKBP12.6 gene in cases.

\begin{tabular}{|c|c|c|c|c|c|}
\hline Gene & Site & SNP & Troca & $\begin{array}{c}\text { MAF: cases } \\
(\mathrm{n}=186)\end{array}$ & $\begin{array}{l}\text { MAF: dbSNP } \\
\text { (YRI - CEU) }\end{array}$ \\
\hline FKBP12 & Intron 2 & rs6074549 & $C / G$ & 0.0026 & $0.008-0$ \\
\hline \multirow[t]{6}{*}{ FKBP12.6 } & Exon $1-5^{\prime}$ UTR & rs116520786 & $\mathrm{C} / \mathrm{T}$ & 0.14 & $0.25-0$ \\
\hline & Exon 1 - 5' UTR & rs111634163 & $\mathrm{C} / \mathrm{T}$ & 0.06 & NA \\
\hline & Intron 3 & rs13016301 & $\mathrm{A} / \mathrm{T}$ & 0.07 & $0-0.18$ \\
\hline & Intron 3 & rs1424344 & $\mathrm{C} / \mathrm{T}$ & 0.18 & $0.32-0$ \\
\hline & Exon 4 - 3'UTR & rs14388 & $\mathrm{C} / \mathrm{T}$ & 0.17 & $0.4-0.008$ \\
\hline & Exon 4 - 3'UTR & rs114658911 & $\mathrm{C} / \mathrm{T}$ & 0.005 & $0-0.005$ \\
\hline
\end{tabular}

MAF: Minor Allele Frequency; NA: Not Available; CEU: Northern and Western Europe; YRI: Yoruba in Ibadan, Nigeria

\section{Methods}

\section{Study population}

One-hundred-eighty-six (186) patients with Idiopathic Dilated Cardiomyopathy (IDC) were selected from two different heart failure cohorts from the Heart Institute (InCor), University of São Paulo Medical School. In both groups, the diagnosis of heart failure was made according to previously published criteria $[21,22]$. The heart failure etiology classification followed previous recommendations[22]. As such, the diagnosis of chronic heart failure was made through both clinical and imaging procedures when necessary. Ischemic cardiomyopathy diagnosis was made when a clear history of previous myocardial infarction and no other probable causes of heart dysfunction were present or, alternatively, through coronary angiography. All patients with the final diagnosis of idiopathic dilated cardiomyopathy were studied through coronary angiography to exclude the diagnosis of ischemic cardiomyopathy. Table 3 shows clinical and functional characteristics of the IDC Cohort.

\section{Molecular Genetic Analyses}

Extraction of genomic DNA was performed from leukocytes separated from whole blood using a standard saltingout method [23]. DNA samples were further diluted with PCR grade water to a concentration of $10 \mathrm{ng} / \mu \mathrm{L}$. All coding exons and flanking sequences of FKBP12 (reference sequence: NM_000801.3) and FKBP12.6 (reference sequence: NM_004116.3) were analyzed for mutations, with at least 20 nucleotides into introns. Intronic primers were designed using the software Primer3 [24]. The final optimal reaction conditions were empirically determined; primer sequences are described in Table 4, and PCR conditions are available upon request. Samples were preselected for bidirectional sequencing by High-Resolution Melting (HRM) curves manually analyzed or were bidirectionally sequenced directly. For HRM, the reaction mixture used BioTaq DNA Polymerase (BioQuimica, Brazil) and consisted of $10 \mathrm{ng}$ of genomic DNA, 1× Assay buffer, $2 \mathrm{mM} \mathrm{MgCl} 2,200 \mathrm{nM}$ of each primer, $200 \mu \mathrm{M}$ of dNTPs, 1,5 $\mu \mathrm{M}$ of SYTO9 (Invitrogen, Carlsbad, USA), $0.5 \mathrm{U}$ of
BioTaq DNA Polymerase and PCR grade water in a volume of $10 \mu \mathrm{L}$. PCR cycling and HRM analysis were performed on the Rotor-Gene ${ }^{\mathrm{TM}} 6000$ equipment (Qiagen, Courtaboeuf, France). Bidirectional sequencing was performed by 3500xL Genetic Analyzer (Applied Biosystems, EUA) using BigDye ${ }^{\circledR}$ Terminator v3.1 Cycle Sequencing Kit (Applied Biosystems, EUA) and manufacturer protocols. The frequency of all identified variants was determined in 288 age and ethnic matched controls by HRM.

The importance of variants out of coding regions that were not present in the control sample was analyzed in silico by FastSNP[17], MutationTaster [15] and

\section{Table 3 Clinical and functional characteristics of IDC} Cohort

\begin{tabular}{lc}
\hline \multicolumn{2}{c}{ IDC Cohort } \\
\hline Clinical \\
Biochemical \\
$\quad$ Hemoglobin (mg/dL) \\
$\quad$ Total Cholesterol (mg/dL) \\
$\quad$ Triglycerides (mg/dL) \\
$\quad$ HDL (mg/dL) & $185 \pm 1.97$ \\
$\quad$ LDL (mg/dL) & $106 \pm 56$ \\
$\quad$ Creatinin (mg/dL) & $45.7 \pm 17.3$ \\
BMl (kg/m $\left.{ }^{2}\right)$ & $116 \pm 44$ \\
Heart Rate (pm) & $1.2 \pm 0.3$ \\
Diastolic Blood Pressure (mmHg) & $25.08 \pm 4.65$ \\
Systolic Blood Pressure (mmHg) & $76.35 \pm 13.57$ \\
Echocardiographic & $67.41 \pm 14.56$ \\
Left Atrium Diameter, mm & $104.44 \pm 18.9$ \\
Aortic Diameter, mm & \\
Right Ventricle Diameter, mm & $47.52 \pm 8.48$ \\
Left Ventricle & $32.57 \pm 4.26$ \\
$\quad$ Intraventricular Septum, mm & $27.19 \pm 6.14$ \\
$\quad$ Posterior Wall Thickness, mm & \\
Diastolic Diameter, mm & $8.39 \pm 1.48$ \\
Systolic Diameter, mm & $8.31 \pm 1.21$ \\
Ejection Fraction, $(\%)$ & $73.55 \pm 10.06$ \\
Mass, g & $64.01 \pm 9.58$ \\
\hline
\end{tabular}


Table 4 Primers for FKBP12 and FKBP12.6 amplification of coding exons and flanking region sequences

\begin{tabular}{|c|c|c|c|}
\hline Gene & Exon & Primer & Amplicon \\
\hline \multirow[t]{8}{*}{ FKBP12 } & $1 F$ & 5'- TCTCGGGGCTTCTGGGCTTC -3' & 269 \\
\hline & $1 \mathrm{R}$ & 5'- GCGCCACTACTCACCGTCTC -3' & \\
\hline & $2 \mathrm{~F}$ & 5'- CATGCCCGTCTCTGTCTCCTCA -3' & 242 \\
\hline & $2 \mathrm{R}$ & 5'- AAGCCCCAGGCTGCCCCTGA -3' & \\
\hline & $3 F$ & 5'- TGCTGCTGGTTTCTGACTTGT -3' & 299 \\
\hline & $3 R$ & 5'- TGGCATGAGGGTGAGACTITC -3' & \\
\hline & $4 \mathrm{~F}$ & 5'- TTCTTACAGAGACAGTTGGGG -3' & 253 \\
\hline & $4 \mathrm{R}$ & 5'- GCCCTTCAGTATTCCATTTCCT -3' & \\
\hline \multirow[t]{8}{*}{ FKBP12.6 } & $1 \mathrm{~F}$ & 5'- GAATGGATGGATGGAGGATG -3' & 527 \\
\hline & $1 \mathrm{R}$ & 5'- TCCTAGACCCCCAAGAATCC -3' & \\
\hline & $2 \mathrm{~F}$ & 5'-CCAGAGAGGTGACGTGA-3' & 390 \\
\hline & $2 \mathrm{R}$ & 5'-TAGACTGGCTGGGAGGA-3' & \\
\hline & $3 F$ & 5'-GGGAGTTTACTCATGACCA-3' & 368 \\
\hline & $3 R$ & 5'-CAGGGACACAAAAGAGGTA-3' & \\
\hline & $4 \mathrm{~F}$ & 5'-CAGTCACATCTCTGCTGA-3' & 510 \\
\hline & $4 \mathrm{R}$ & 5'-CGCATGAACACTGACGAA-3' & \\
\hline
\end{tabular}

miTarget [16]; concerning the transcription factor binding site, splicing and miRNA binding sites, respectively.

\section{Statistical analysis}

Data are presented as mean \pm standard deviation (SD) for continuous variables and as frequencies for categorical variables. Statistical analyses were performed with SPSS software 13.0. Hardy-Weinberg equilibrium was evaluated by a Chi-square test. Allelic frequencies comparison was evaluated Fisher's exact test.

\section{Ethics Statement}

The investigation conforms to the principles outlined in the Declaration of Helsinki and the study protocol was approved by the Ethics Committee for Medical Research on Human Beings of the Hospital das Clínicas from University of São Paulo Medical School. Signed informed consent was obtained from all participants from both samples.

\section{List of abbreviations}

A: Adenine; C: Cytosine; CCD: Central Core Disease; CPVT: Catecholaminergic Polymorphic Ventricular Tachycardia; DCM: Dilated Cardiomyopathy; G: Guanine; IDC: Idiopathic Dilated Cardiomyopathy; LVNC: Left Ventricule Noncompaction; MAF: Minor Allelic Frequency; RyRs: Ryanodine Receptors; SNP: Single Nucleotide Polymorphism; SR: Sarcoplasmic Reticulum; T: Thymine; TF: Transcription Factor; UTR: Untranslated region.

\section{Acknowledgements}

We thank FAPESP - Fundação de Amparo à Pesquisa do Estado de São Paulo for the financial support. (Grant Number: 2008/51652-0). We thank André Vaquero, Arnaldo Menezes, Camila Bonin, Débora Leite, Fernanda Sodré and Samantha Kuwada for English revision.

\section{Author details}

'Laboratory of Genetic and Molecular Cardiology, Heart Institute, University of Sao Paulo Medical School, Brazil. ${ }^{2}$ Department of Physiology, Federal University of Espírito Santo, Vitória, Brazil. ${ }^{3}$ Heart Institute, University of Sao Paulo Medical School, Brazil.

\section{Authors' contributions}

DGB participated in the design of the study, carried out the molecular genetic studies, analyses and drafted the manuscript. AJM coordinated the creation of the studied population. JGM coordinated the creation of the control population. JEK participated in the design of the study. ACP participated in the design and coordination of the study and helped to draft the manuscript. All authors read and approved the final manuscript.

\section{Competing interests}

The authors declare that they have no competing interests.

Received: 1 May 2011 Accepted: 11 January 2012

Published: 11 January 2012

\section{References}

1. Lanner JT, Georgiou DK, Joshi AD, Hamilton SL: Ryanodine receptors: structure, expression, molecular details, and function in calcium release. Cold Spring Harb Perspect Biol 2010, 2:a003996.

2. Timerman AP, Ogunbumni E, Freund E, Wiederrecht G, Marks AR, Fleischer S: The calcium release channel of sarcoplasmic reticulum is modulated by FK-506-binding protein. Dissociation and reconstitution of FKBP-12 to the calcium release channel of skeletal muscle sarcoplasmic reticulum. J Biol Chem 1993, 268:22992-22999.

3. Timerman AP, Onoue H, Xin HB, Barg S, Copello J, Wiederrecht G, Fleischer S: Selective binding of FKBP12.6 by the cardiac ryanodine receptor. J Biol Chem 1996, 271:20385-20391.

4. Jeyakumar LH, Ballester L, Cheng DS, Mclntyre JO, Chang P, Olivey HE, Rollins-Smith L, Barnett JV, Murray K, Xin HB, Fleischer S: FKBP binding characteristics of cardiac microsomes from diverse vertebrates. Biochem Biophys Res Commun 2001, 281:979-986.

5. Brillantes AB, Ondrias K, Scott A, Kobrinsky E, Ondriasova E, Moschella MC, Jayaraman T, Landers M, Ehrlich BE, Marks AR: Stabilization of calcium release channel (ryanodine receptor) function by FK506-binding protein. Cell 1994, 77:513-523.

6. Gaburjakova M, Gaburjakova J, Reiken S, Huang F, Marx SO, Rosemblit N, Marks AR: FKBP12 binding modulates ryanodine receptor channel gating. J Biol Chem 2001, 276:16931-16935.

7. Wehrens XH, Lehnart SE, Huang F, Vest JA, Reiken SR, Mohler PJ, Sun J, Guatimosim S, Song LS, Rosemblit N, et al: FKBP12.6 deficiency and defective calcium release channel (ryanodine receptor) function linked to exercise-induced sudden cardiac death. Cell 2003, 113:829-840.

8. Shou W, Aghdasi B, Armstrong DL, Guo Q, Bao S, Charng MJ, Mathews LM, Schneider MD, Hamilton SL, Matzuk MM: Cardiac defects and altered ryanodine receptor function in mice lacking FKBP12. Nature 1998, 391:489-492.

9. Xin HB, Senbonmatsu T, Cheng DS, Wang YX, Copello JA, Ji GJ, Collier ML, Deng KY, Jeyakumar LH, Magnuson MA, et al: Oestrogen protects FKBP12.6 null mice from cardiac hypertrophy. Nature 2002, 416:334-338.

10. Marjamaa A, Laitinen-Forsblom P, Lahtinen AM, Viitasalo M, Toivonen L, Kontula $\mathrm{K}$, Swan H: Search for cardiac calcium cycling gene mutations in familial ventricular arrhythmias resembling catecholaminergic polymorphic ventricular tachycardia. BMC Med Genet 2009, 10:12.

11. Chiu C, Tebo M, Ingles J, Yeates L, Arthur JW, Lind JM, Semsarian C: Genetic screening of calcium regulation genes in familial hypertrophic cardiomyopathy. J Mol Cell Cardiol 2007, 43:337-343.

12. Oyama MA, Chittur SV, Reynolds CA: Decreased triadin and increased calstabin2 expression in Great Danes with dilated cardiomyopathy. J Vet Intern Med 2009, 23:1014-1019.

13. Kenton AB, Sanchez X, Coveler KJ, Makar KA, Jimenez S, Ichida F, Murphy RT, Elliott PM, McKenna W, Bowles NE, et al: Isolated left ventricular noncompaction is rarely caused by mutations in G4.5, alphadystrobrevin and FK Binding Protein-12. Mol Genet Metab 2004, 82:162-166. 
14. Wu S, Ibarra MC, Malicdan MC, Murayama K, Ichihara Y, Kikuchi H, Nonaka I, Noguchi S, Hayashi YK, Nishino I: Central core disease is due to RYR1 mutations in more than $90 \%$ of patients. Brain 2006, 129:1470-1480.

15. Schwarz JM, Rodelsperger C, Schuelke M, Seelow D: MutationTaster evaluates disease-causing potential of sequence alterations. Nat Methods 2010, 7:575-576.

16. Wang $X$ : miRDB: a microRNA target prediction and functional annotation database with a wiki interface. RNA 2008, 14:1012-1017.

17. Yuan HY, Chiou JJ, Tseng WH, Liu CH, Liu CK, Lin YJ, Wang HH, Yao A, Chen YT, Hsu CN: FASTSNP: an always up-to-date and extendable service for SNP function analysis and prioritization. Nucleic Acids Res 2006, 34 W635-641.

18. Ball AM, Sole MJ: Oxidative stress and the pathogenesis of heart failure. Cardiol Clin 1998, 16:665-675, viii-ix.

19. Singal PK, Khaper N, Palace V, Kumar D: The role of oxidative stress in the genesis of heart disease. Cardiovasc Res 1998, 40:426-432.

20. Seidler T, Loughrey CM, Zibrova D, Kettlewell S, Teucher N, Kogler H, Hasenfuss G, Smith GL: Overexpression of FK-506 binding protein 12.0 modulates excitation contraction coupling in adult rabbit ventricular cardiomyocytes. Circ Res 2007, 101:1020-1029.

21. Hunt SA: ACC/AHA 2005 guideline update for the diagnosis and management of chronic heart failure in the adult: a report of the American College of Cardiology/American Heart Association Task Force on Practice Guidelines (Writing Committee to Update the 2001 Guidelines for the Evaluation and Management of Heart Failure). J Am Coll Cardiol 2005, 46:e1-82.

22. McKee PA, Castelli WP, McNamara PM, Kannel WB: The natural history of congestive heart failure: the Framingham study. N Engl J Med 1971, 285:1441-1446.

23. Miller SA, Dykes DD, Polesky HF: A simple salting out procedure for extracting DNA from human nucleated cells. Nucleic Acids Res 1988, 16:1215.

24. Koressaar T, Remm M: Enhancements and modifications of primer design program Primer3. Bioinformatics 2007, 23:1289-1291.

doi:10.1186/1477-5751-11-4

Cite this article as: Biagi et al: A negative screen for mutations in calstabin 1 and 2 genes in patients with dilated cardiomyopathy. Journal of Negative Results in BioMedicine 2012 11:4.

\section{Submit your next manuscript to BioMed Central and take full advantage of:}

- Convenient online submission

- Thorough peer review

- No space constraints or color figure charges

- Immediate publication on acceptance

- Inclusion in PubMed, CAS, Scopus and Google Scholar

- Research which is freely available for redistribution

Submit your manuscript at www.biomedcentral.com/submit 